\title{
Artioo Orainal \\ EVIDÊNCIA DE EFICÁCIA DE COBERTURA DE SAPATOS E SAPATOS PRIVATIVOS NO CONTROLE E PREVENÇÃO DE INFECÇÃO DO SÍTIO CIRÚRGICO: REVISÃO SISTEMÁTICA DE LITERATURA
}

\author{
Alice Medeiros Lutz Santos ${ }^{1}$ \\ RúbiaAparecida Lacerda ${ }^{2}$ \\ Kazuko Uchikawa Graziano ${ }^{2}$
}

Santos AML, Lacerda RA, Graziano KU. Evidência de eficácia de cobertura de sapatos e sapatos privativos no controle e prevenção de infecção do sítio cirúrgico: revisão sistemática de literatura. Rev Latino-am Enfermagem 2005 janeiro-fevereiro; 13(1):86-92.

O estudo refere-se a propés e sapatos privativos, realizado em 2003, e teve como objetivo a busca de evidência científica sobre sua relação direta no controle de contaminação e/ou infecção do ar ambiente e do sítio cirúrgico por microrganismos oriundos do piso. A metodologia utilizada foi a revisão sistemática de pesquisas básicas, desde 1950 até 2003, por meio de busca em fontes eletrônicas, bibliografias de estudos relevantes e anais de eventos científicos. Do total de publicações encontradas, somente 10 constituíram pesquisas básicas, as quais foram analisadas quanto ao escopo, tipo de investigação, metodologia, resultados, conclusões e comentários dos analisadores. A análise foi auxiliada por dois pesquisadores, ambos com experiência na temática e um em metodologia de pesquisa. Observou-se, nesta análise, diversidade e problemas dos métodos de investigação utilizados, sendo que apenas 4 pesquisas obtiveram dispersão de microrganismos do piso para o ar ambiente, porém não significativa, e nenhuma relacionada diretamente com contaminação e/ou infecção do sítio cirúrgico. Obteve-se evidências sobre: 1) a capacidade de barreira e de transferência de microrganismos no piso de uma área para outra depende do tipo de cobertura de sapatos; 2) contaminação ocupacional durante remoção e colocação de propés. Como conclusão, não há evidência de que propés e sapatos privativos evitem a contaminação do ambiente e da ferida cirúrgica, e a decisão pela continuidade do seu uso precisa ser técnica e administrativamente controlada.

DESCRITORES: infecção da ferida operatória; centro cirúrgico hospitalar; ambiente de instituições de saúde

\section{EVIDENCE OF CONTROL AND PREVENTION OF SURGICAL SITE INFECTION BY SHOE COVERS AND PRIVATE SHOES - A SYSTEMATIC LITERATURE REVIEW}

The study is about shoe cover and private shoe usage and aimed to find scientific evidence on their direct relation in the control of surgical site contamination and/or infection transmitted by floor microorganisms. A systematic review of basic research on shoe covers and private shoes usage was carried out, covering the period from 1950 to 2003, by means of a search in electronic sources, bibliographies of relevant studies and proceedings of scientific events. The analysis was supported by two researchers, both of whom were experienced in this theme and one of them in research methodology. The research methods revealed a diverse range and various problems. Only 4 studies obtained a dispersion of floor microorganisms to the air environment, although not significant, and none of them was directly related to surgical site contamination and/or infection. Results do not suggest direct evidence on their efficacy but there is evidence, nonetheless, that barrier and microorganisms transfer from one specific area to another depend on the type of shoe cover, with lower transfer rates when private shoes and shoe covers are employed. Occupational contamination risk during shoe cover attire and removal is also evident and the decision about continuity of their usage needs to be technically and administratively controlled.

DESCRIPTORS: surgical wound infection; surgery department, hospital; health facility environment

\section{EVIDENCIAS DE CONTROL Y PREVENCIÓN DE INFECCIONES DEL SITIO QUIRÚRGICO CON CALZADOS DE SEGURIDAD Y ZAPATOS EXCLUSIVOS - REVISIÓN SISTEMÁTICA DE LITERATURA}

Este estudio de revisión sistemática de investigaciones básicas sobre calzados de seguridad y zapatos exclusivos buscó evidencias de su eficacia en el control de la contaminación e infección del sitio quirúrgico por microorganismos del ambiente procedentes del piso. Fueron identificadas 10 investigaciones básicas a partir de una búsqueda electrónica y de listas de referencias de artículos de relevancia, en el período de 1950 a 2003, que fueron analizadas de acuerdo con: el objetivo, el tipo de investigación, el diseño metodológico, los resultados, las conclusiones y los comentarios de los investigadores. Los resultados no sugieren evidencia directa de esta eficacia, aunque hay evidencias de que la capacidad de barrera y de transferencia de microorganismos de un área para otra del piso depende del tipo de calzados de seguridad, siendo menor con zapatos exclusivos y calzados de seguridad. El riesgo de contaminación ocupacional durante la remoción y la puesta de calzados de seguridad también es evidente. La decisión por la continuidad del uso de estos elementos necesita ser controlada técnica y administrativamente.

DESCRIPTORES: infección de herida operatoria; servicio de cirugía en hospital; ambiente de instituciones de salud

${ }^{1}$ Enfermeira graduada; ${ }^{2}$ Enfermeira, Professor Associado, e-mail: rlacerda@usp.br. Escola de Enfermagem da Universidade de São Paulo 


\section{INTRODUÇÃO}

Sapatos privativos e propés constituem barreiras contra microrganismos carreados nas solas dos sapatos comuns. A sua importância no controle da infecção do sítio cirúrgico (ISC) está na possibilidade da contaminação do piso atingir a incisão aberta, a qual pode ocorrer de dois modos: 1- contato de objetos e mãos que tocam piso e sapatos; 2- dispersão de microrganismos do piso para o ar ambiente $^{(1)}$. Essas barreiras estão relacionadas com a segunda possibilidade, pois, na primeira, a questão depende de práticas corretas de precauções de contato. No entanto, sapatos comuns não constituem a única fonte de contaminação microbiana do piso de uma sala de operação. Outras fontes são: rodas de equipamentos móveis, vassouras úmidas (mops), substâncias orgânicas e materiais que caem no chão, etc. ${ }^{(2)}$.

O uso dessas barreiras em centro cirúrgico tem sido discutido na literatura cientifica desde meados do século XX, ora defendendo-as e ora refutando-as com base em resultados divergentes de pesquisas. Ainda não existe, porém, avaliação da qualidade das metodologias utilizadas e a evidência de seus resultados. Este estudo teve como objetivo a busca de evidência científica de contaminação e infecção do sítio cirúrgico por microrganismos do ambiente, oriundos do piso e das solas de sapatos comuns, a partir da análise de pesquisas básicas.

\section{MATERIAL E MÉTODO}

Trata-se de investigação retrospectiva de revisão sistemática, cujas etapas operacionais basearam-se no Curso online de Revisão Sistemática e Metanálise, do Centro Cochrane do Brasil e do Laboratório de Ensino à Distância do Departamento de Informática em Saúde da Escola Paulista de Medicina da Universidade Federal de São Paulo (http://www.virtual.epm.br/cursos/metanalise/index/htm). A estratégia metodológica apoiou-se no estudo de revisão sistemática de Kjonniksen ${ }^{(3)}$.

A questão básica que norteia a investigação é: propés e sapatos privativos são eficazes no controle de contaminação do ar ambiente e de infecção do sítio cirúrgico?

As unidades de análise foram constituídas de pesquisas básicas* sobre sapatos privativos, propés e dispersão de microrganismos do chão ao ar ambiente, que os relacionem com contaminação ou infecção do sítio cirúrgico. As fontes foram as bases eletrônicas MEDLINE, LILACS e PUBMED, desde a década de 50 do século XX até 2003. Outras buscas foram Anais dos Congressos Brasileiros de Controle de Infecção e Epidemiologia Hospitalar (2000 e
2002) e Congressos Brasileiros de Enfermagem (1990 a 2003) e as referências bibliográficas das próprias publicações encontradas.

As palavras-chaves utilizadas foram: footwear, shoe covers, foot attachments, surgical attire, garb, overshoes, cruzadas com as palavras: operating room, theatre, surgical infection, infection control, contamination air e contamination environment, além de airbone, dispersal, bacteria e floor, combinadas entre si. Um total de 112 publicações foram encontradas, sendo desconsideradas aquelas cujos títulos ou resumos permitiram antecipadamente concluir que não se tratavam de pesquisas básicas ou não se relacionavam à questão específica desta investigação. Das remanescentes, procedeu-se à busca da publicação completa em bibliotecas especializadas, sendo que sete não foram encontradas, totalizando dez pesquisas básicas.

A classificação do tipo de pesquisa baseou-se em Polit e Hungler ${ }^{(4)}$ e Talbot ${ }^{(5)}$, constituindo: a) experimental-intervenção em um grupo e tendo outro como controle, randomizada, duplo ou triplo cego, com testes estatísticos inferenciais; b) quase-experimental-intervenção existente, porém sem grupo, comparando-se antes e depois da intervenção, com testes estatísticos inferenciais; c) não experimentalcoleta os dados sem introdução de quaisquer tratamentos ou mudanças novas, sendo subclassificada em: c.1) exploratória/descritiva, quando apresenta retrato preciso das características de indivíduos, situações ou grupos e da freqüência com que ocorrem determinados fenômenos; c.2) comparativa/correlacional, quando explora inter-relações entre variáveis de interesse, sem intervenção ativa do pesquisador, sendo necessários testes estatísticos inferenciais para comparar resultados iguais ou diferentes. Uma classificação adicional também foi considerada: d) quanto ao cenário- laboratorial $x$ campo; e) quanto ao tipo de experimento- microbiológico e/ou epidemiológico.

A análise foi realizada com a colaboração de dois pesquisadores das áreas de controle de infecção hospitalar, centro cirúrgico e centro de material, ambos com experiência em estudos epidemiológicos e um deles também em microbiológicos e ensino de metodologia de pesquisa. As pesquisas analisadas são citadas a seguir. 1. Humphreys H, Marshall RJ, Ricketts VE, Russel AJ, Reeves DS. Theatre over-shoes do not reduce operating theatre floor bacterial counts. J Hosp Infect 1991; 17:117-123.

2. Carter R. Ritual and risk. Nurs Times 1990; 86(13):63-4.

3. Graziano KU. Uso de propés no controle de contaminação do piso da sala de operação. Congresso Bras. de Enf., 43 Curitiba, 1991. Programa. Curitiba: Associação Brasileira de Enfermagem; 1991. p. 158.

4. Copp G, Slezak L, Dudley N, Mailhot CB. Footwear practices and operating room contamination. Nurs Res 1987; 36(6):366-9.

5. Chou T, Summers PR, Biswas MK, Portera SG, Moore L. Blood-

* Pesquisas básicas: testam intervenções ou controlam/correlacionam/comparam efeitos de variáveis em um dado fenômeno, incluindo ou não grupos controle, sob condições laboratoriais ou de campo, independente da temporalidade. São também denominadas pesquisas primárias 
saturated operating-room shoe covers. West J Med 1992; 157(2):184-

5 .

6. Duquette-Petersen L, Francis ME, Dohnalek L, Skinner R, Dudas

$P$. The role of protective clothing in infection prevention in patients undergoing autologous bone marrow transplantation. Oncol Nurs Forum 1999; 26(8):1319-24.

7. Hambraeus A, MalmborgAS. The influence of different footwear on floor contamination. Scand J Infect Dis 1979; 11(3):243-6.

8. Pereira SN, Gaida F, Tholozan LN, Palma J. Influência do uso de propés no controle da contaminação ambiental da U.T.I. do Hospital Universitário de Santa Maria/Influence of the use of surgical book in the control of contamination in the intensive care unit of the Hospital Universitário de Santa Maria. Saúde. Santa Maria 1985; 11(1/2):13542.

9. Hambraeus A, Bengtsson S Laurell G. Bacterial contamination in a modern operating suite. 3. Importance of floor contamination as a source of airbone bacteria. Hyg 1978; 80:169.

10. Ayliffe GAJ, Collins BJ, Lowbury EJL. Ward floors and other surfaces as reservoirs of hospital infection. Hyg 1967; 65:515-36.

NOTA: a citação 10 trata-se de uma compilação de pesquisas, tendo sido analisada aquela que correspondia à questão básica desta revisão, intitulada Redispersal of bacteria from floors into the air.

\section{RESULTADOS}

As pesquisas são apresentadas conforme a classificação ${ }^{(3)}$, que considera: escopo, resultados, conclusões, comentários dos analisadores. A essa classificação foram acrescentados o tipo de pesquisa e o desenho metodológico.

Estudo 1

Escopo: contaminação do piso da sala de operação pelos visitantes com e sem propés.

Tipo de estudo: experimental, randomizado, microbiológico, de campo, com análise de valores médios, desvios padrão, coeficientes de variação e cálculo de significância.

Desenho: profissionais com sapatos privativos e visitantes com e sem propés de PVC. Culturas do piso foram realizadas 4 vezes/dia em 5 dias de trabalho, durante 1-2 semanas seqüenciais, em uma mesma sala de operação, sob mesmas condições de limpeza. Foram controlados o potencial de contaminação das cirurgias.

Resultados: diferença não significativa na contagem bacteriana total com e sem propés nos diferentes horários. Houve amostras de maior contagem com uso de propés.

Conclusões: propés não reduzem significativamente a contagem bacteriana do piso.
Comentários: variáveis que podem ter interferido na contagem bacteriana do piso não foram controladas, como intensidade de trânsito e seu período de permanência em cada fase.

\section{Estudo 2}

Escopo: verificar a contaminação das mãos com solas de sapatos e de propés de plástico em UTI e a prática de lavagem das mãos.

Tipo de estudo: exploratório/descritivo, de campo, microbiológico.

Desenho: foram estudadas culturas microbianas de dedos de profissionais antes e após colocação e remoção dos propés, comparadas com as solas dos sapatos antes da sua colocação e antes da remoção dos propés.

Resultados: aumento de microrganismos nos dedos após colocação ou remoção de propés. Maior contagem de microrganismos no piso do corredor limpo e nas solas dos propés do que nos sapatos no primeiro ensaio e o contrário no segundo ensaio. $79 \%$ relatou que normalmente não lavava as mãos após colocação e remoção de propés.

Conclusões: propés não isolam microrganismos e não são necessários para isolamento de pacientes com infecção, mas recomenda-se o uso de sapatos limpos no centro cirúrgico. Mãos podem ser contaminadas com microrganismos das solas de propés e sapatos.

Comentários: estudo sem análise estatística de significância, desvios padrão ou coeficiente de variação e não controle de período de uso dos propés. Não permite comprovar se maior contagem nas mãos no segundo ensaio é oriunda dos propés e sapatos, ou de outras fontes. Sugestão apresentada pelos autores para os resultados opostos em dois ensaios não é comprovada pela pesquisa.

\section{Estudo 3}

Escopo: determinar a eficácia de propés de sola de brim como barreira antimicrobiana e correlacionar microrganismos do piso da sala de operação com aqueles do ar após cirurgias.

Tipo de estudo: quase-experimental, microbiológico, de campo, análise estatística de significância e observação de frequêencia de lavagem de mãos na colocação e remoção de propés.

Desenho: cultura de: a) piso da SO antes e após cirurgias pediátricas limpas e eletivas; b) solas dos sapatos da equipe antes da colocação de propés estéreis na entrada da SO; c) solas dos propés antes da saída da SO; d) ar ambiente um pouco antes do término das cirurgias. Resultados: significância na eficácia de isolamento microbiano da sola de sapatos com propé de brim. Culturas do ambiente não evidenciaram associação direta com microrganismos das solas de sapatos e de propés. Conclusões: caso haja o propósito de valorizar o controle da contaminação do piso, a sola do propé de brim constitui barreira eficaz. Comentários: controle de diversas variáveis, porém não especifica se a cultura do ar foi obtida após cada cirurgia ou após todas as cirurgias. 


\section{Estudo 4}

Escopo: verificar se ocorre redução de transferência de bactérias para área restrita do centro cirúrgico, usando cobertura de sapatos.

Tipo de estudo: experimental, randomizado, de campo, microbiológico, análise estatística com testes não-paramétricos e níveis de significância. Desenho: 51 voluntários, de um total de 61, rodiziando-se durante 5 semanas nos grupos: a) sapatos de rua na área de estudo; b) sapatos privativos calçados no vestiário; c) propés colocados no vestiário; d) sapatos privativos calçados antes de caminhar na área de estudo; e) propés colocados antes de caminhar na área de estudo. Testes: a) início da manhã antes do tráfego e após desinfecção do piso; b) meio da manhã após tráfego e sem desinfecção. Amostras antes e após caminhadas.

Resultados: variações de bactérias ora significativas ora não significativas entre os grupos, de acordo com horário e forma de caminhada.

Conclusões: sapatos de rua transferem mais bactérias do que privativos e propés. Local de colocação de propés não foi significativo. Propés transferem menos bactérias para áreas limpas do que sapatos privativos. Comentários: metodologia bem delineada e controlada. Sapatos limpos e, principalmente, propés conferem barreira e menor contaminação do piso.

\section{Estudo 5}

Escopo: verificar a ocorrência de contaminação dos propés com sangue do piso e riscos durante sua remoção.

Tipo de estudo: exploratório/descritivo de campo, microbiológico.

Desenho: exames de propés utilizados no centro cirúrgico durante dois dias para confirmação de presença de sangue por teste de fenolftaleína. Observação dos cirurgiões durante remoção dos propés. Resultados: maioria dos propés apresentava sangue na parte externa ou interna. Muitos profissionais não usaram luvas para sua remoção e andaram descalços no vestiário. Luvas dos investigadores sujaram-se com sangue. A maioria dos cirurgiões usou propés com sangue no vestiário e não lavou as mãos após sua remoção.

Conclusões: propés contaminam o chão do vestiário com sangue e saturam os sapatos e a sua retirada aumenta o risco de exposição. Propés devem ser removidos com luvas antes da entrada no vestiário. Comentários: evidência de contaminação de propés com sujidade do piso, sua transferência para outros locais e risco de contaminar sapatos e mãos durante a sua remoção.

\section{Estudo 6}

Escopo: verificar a eficácia de aventais e propés na prevenção de infecção em pacientes submetidos a transplante de medula óssea.
Tipo de estudo: experimental, randomizado, de campo, epidemiológico. Desenho: 31 adultos em quartos individuais, após transplante de medula óssea pela primeira vez e sem antibioticoterapia pré-transplante, sob sistema de ar com alta eficiência de filtração de partículas (HEPA). Uso de aventais e propés para cuidados no grupo controle e não uso no experimental. Variáveis controladas: início da antibioticoterapia e período do tratamento. Os propés e aventais eram colocados e retirados a cada entrada e saída dos quartos.

Resultados: não houve diferenças significativas de períodos entre transplante e primeira dose de antibiótico e período de tratamento entre os dois grupos. A idade pareceu ser fator importante para início mais tardio do tratamento.

Conclusões: paramentação não demonstrou benefícios. 0 poder estatístico foi mínimo e não aumentou o período de início do tratamento, tampouco diminuiu sua duração.

Comentários: estudo bem controlado, com poder estatístico forte, apesar de amostra pequena. Porém, ao utilizar outro item de paramentação (avental) não permite averiguar o papel isolado dos propés.

\section{Estudo 7}

Escopo: interferência da caminhada e de 3 tipos de calçados na contaminação do piso.

Tipo de estudo: quase experimental, comparativo, microbiológico, de campo.

Desenho: áreas semelhantes com e sem trânsito, desinfetadas pela manhã. Investigação de contaminação após a limpeza e após 4 horas sem trânsito. Contaminação do piso com 3 tipos de cobertura dos pés em dias alternados: a) propés novos e transitados no departamento; $b$ ) sapatos desinfetados e usados apenas no local de teste; c) sapatos comuns. Amostras para cultura de 3 lugares diferentes, em 3 períodos (7, 12 e 14 horas).

Resultados: áreas sem trânsito 7 a 16 vezes menos contaminadas. S. aureus obtidos em 5 ocasiões (2 dias nas áreas com trânsito e 3 nas sem trânsito). Segundo horário (12h) com maior contagem do que 0 primeiro (7h). Pouca diferença entre segunda e terceira amostra e entre tipos de coberturas de sapatos. Total no final do dia mais alto do que no meio do dia. Não foi possível mostrar diferença significativa na contaminação do piso de acordo com as diferentes rotinas de uso de propés.

Conclusões: os resultados não demonstram diferença significativa de contaminação entre propés e sapatos limpos. No entanto, o uso de algum tipo de barreira dos calçados comuns pode ter alguma influência na redução da contaminação do piso, uma vez que no período da manhã ela foi mais baixa e parece ter ocorrido por contato e não por sedimentação oriunda do ar.

Comentários: estudo bem controlado, mas sem análise de significância estatística. Inferência de que o piso é mais contaminado quando pessoas 
nele caminham. Propés e sapatos limpos contaminam menos do que sapatos comuns.

\section{Estudo 8}

Escopo: verificar a influência do uso de propés na contaminação do ar ambiente da UTI.

Tipo de estudo: quase-experimental, comparativo, microbiológico, de campo, com análise estatística de significância.

Desenho: testes: a) uso irregular de propés; b) não uso; c) uso correto. Culturas em 3 turnos diários por 5 dias em 4 leitos, saleta e vestíbulo. Resultados: contaminação significativamente maior na saleta e vestíbulo, de manhã e à tarde em relação à noite, e não significativa entre manhã e tarde e menor à noite em relação à tarde.

Conclusões dos autores: há relação entre locais e turnos de maior movimento e contaminação do ambiente. Uso correto de propés contribui para diminuir o número de colônias do ambiente, talvez ao limitar 0 fluxo de pessoas.

Comentários: estudo apresenta problemas metodológicos, pois não controla o número de funcionários e pacientes, não esclarece tempo de permanência das placas de cultura, não evidencia se menor contaminação é devida ao menor fluxo de pessoas, horários ou uso de propés.

\section{Estudo 9}

Escopo: verificar a ocorrência de redispersão bacteriana do piso de vinil de uma sala de operações ao andar, caminhar e lavar/varrer.

Tipo de estudo: quase-experimental, microbiológico, laboratorial (campo simulado).

Desenho: testes em salas sem ventilação e entradas de ar seladas. Limpeza prévia do piso com álcool 70\% e sua contaminação com S. aureus com sacudidas de roupas da equipe e cobertores de pacientes queimados. Redispersões: a) jato de ar frio de um secador de cabelos no piso; b) limpeza do piso com mop; c) movimentação de 4 pessoas. Uso de paramentação bem fechada durante testes. Mensuração da concentração de S. aureus após sacudidas das roupas. Amostras dos pisos antes da contaminação e após cada redispersão, e do ar após limpeza do piso, após sedimentação, antes e durante as redispersões. Resultados: baixo fator de redispersão em todos os testes, sendo a caminhada 3 vezes mais alta do que o jato de ar e 17 vezes do que a limpeza do piso.

Conclusões: redispersão de S. aureus da poeira do piso para o ar dificilmente aumenta o risco de infecção por bactérias do ambiente. As pessoas que fizeram os testes não podem ser totalmente excluídas como fontes, porque a caminhada foi realizada por 4 pessoas e a ventilação e a limpeza por uma única pessoa. A redispersão pode variar em salas sem e com ventilação sob diferentes trocas de $a r / h, 0$ que influi na velocidade de sedimentação de partículas e de bactérias e no momento da coleta de amostras.

Comentários: o estudo evidencia baixo fator de redispersão de bactérias do piso para o ar, a qual foi obtida em condições mais vigorosas de movimentos do ar do que em situações cotidianas. Não há explicitação dos locais e da altura em que as amostras de ar foram obtidas.

\section{Estudo 10}

Escopo: verificar se ocorre redispersão de bactérias de pisos de vinil e de terrazzo para 0 ar.

Tipo de estudo: quase-experimental, microbiológico, de laboratório (campo simulado).

Desenho: contaminação do ambiente com sacudidas de cobertor de paciente queimado e exercícios físicos de um dispersador, ambos colonizados com S. aureus resistentes a tetraciclina. Amostras do ar após limpeza do piso com álcool 70\%, durante e após a contaminação. Redispersão por meio de: a) jato de ar frio de um secador elétrico na área do piso de máxima contaminação; b) exercícios físicos de uma pessoa não dispersadora; c) varredura do piso com vassoura. Amostras do ar e do piso antes e após o jato de ar, em vários períodos, colhidas por diferentes pessoas não dispersadoras de $S$. aureus, a fim de distinguir possibilidade de contaminação pelas suas roupas. Experimentos realizados em pisos de vinil e de terrazzo.

Resultados: aumento não significativo de organismos no ar pela redispersão com jato de ar no piso de vinil, mas significativo no terrazzo. Maior contaminação do ar pela varredura no terrazzo do que no vinil. Pequeno aumento de microrganismos, mas não de S.aureus, durante exercício de pessoa não dispersadora em ambos os pisos. Redução da contagem total no piso em alguns experimentos, a qual correspondeu ao seu aumento no ar.

Conclusões dos autores: redispersão não significativa de bactérias no ar ambiente.

Comentários: estudo bem controlado, evidencia ocorrência de redispersão, ainda que não significativa, e sob condições exacerbadas em relação a situações cotidianas. No entanto, não cita a altura de coleta de amostras do ar, as condições de ventilação, as formas e os tempos de redispersão pelo exercício físico e pela varredura.

\section{DISCUSSÃO}

É possível concluir que são poucas as pesquisas efetivamente realizadas sobre a relação de propés, sapatos privativos e sapatos comuns com contaminação do ambiente e infecção, correspondendo a cerca de $10 \%$ do total das publicações encontradas. Os sujeitos de 
análise dessas pesquisas foram constituídos predominantemente de piso (7), ar ambiente (4), propés (3), sapatos privativos e sapatos comuns (2), mãos (1) e pacientes (1). Os experimentos foram realizados em situações rotineiras de trabalho (6) e de maneira simulada (4). Os locais foram o centro cirúrgico, incluindo salas de operações (6), UTI (2) e enfermarias (2). A forma de análise foi essencialmente laboratorial, sendo 8 por buscas de microrganismos, 1 de sangue e 1 de contagem de neutrófilos.

Os recursos para análise de cultura microbiológica variaram bastante, seja quanto ao modo de coleta de amostras (pincelagem de cotonete, impressão e exposição de placas com cultura, aspiração de ar), seja quanto aos tipos de culturas (aeróbicas e anaeróbicas), períodos de exposição (de minutos a horas) e de incubação (24 a 48 horas). Variaram também a quantidade de amostras e a forma de análise estatística.

Além dos estudos de metanálise, os de intervenção com ensaios controlados randomizados têm sido os mais consideradas nas classificações internacionais de qualidade de pesquisas quanto à evidência de seus resultados. Em seguida, vêm os quaseexperimentais, que utilizam intervenções e comparam grupos, mas sem locação randomizada ${ }^{(6-7)}$. Dentre as pesquisas analisadas, três correspondem ao tipo experimental randomizado e cinco ao quaseexperimental. Portanto, a maioria dessas pesquisas correspondem às classificações consideradas. Já, as duas outras são do tipo exploratório descritivo, portanto, não utilizam intervenção e comparação. Observase, porém, problemas de controle de variáveis em várias delas, situação que não permite a garantia de obtenção dos mesmos resultados em experimentos repetidos.

Nenhuma pesquisa relacionou contaminação do piso, propés, sapatos privativos e sapatos comuns com contaminação ou infecção do sítio cirúrgico. No entanto, quatro investigaram a redispersão de microrganismos ou partículas do piso para o ar ambiente, sendo que uma delas não obteve amostras de microrganismos coincidentes no piso e no ar sob condições cotidianas em salas de operações. Outra apresenta importantes problemas de desenho metodológico e de controle de variáveis e duas, que podem ser consideradas bem desenhadas e controladas, obtiveram redispersão ao ar ambiente a partir do piso. No entanto, conforme julgam seus próprios autores, ambas foram realizadas sob contaminação deliberada e em condições mais exacerbadas do que o cotidiano em centro cirúrgico. Mesmo assim, os resultados apresentaram baixos fatores de redispersão. Uma vez que uma delas foi realizada em ambiente fechado e sem ventilação, é possível sugerir redispersão ainda mais baixa ou inexistente em ambiente com sistema de ventilação com trocas de ar e sob pressão positiva.
Quatro referências citadas em duas pesquisas analisadas também obtiveram baixo fator de redispersão, porém a sua publicação completa não foi encontrada durante a busca eletrônica e não puderam ser incluídas na análise* . Duas deles contaminaram o piso com poeira radioativa, um com roupa suja e a outra utilizou marcadores biológicos.

A pesquisa original de Ritter e Marmion, muito citada em várias publicações sobre ambiente de sala de operações, também não foi encontrada na busca eletrônica, mesmo utilizando os nomes dos autores como palavra-chave**. Nela, Serratia marcenses foram espalhadas nos pisos e caminhou-se sobre a área contaminada, com coleta de amostras de cultura de vários níveis acima do chão com discos Rodac e esses microrganismos nunca foram obtidos no ambiente.

As outras seis pesquisas analisadas investigaram predominantemente a capacidade de propés, sapatos privativos e sapatos comuns atuarem como barreira contra contaminação e transferência de microrganismos no piso, mãos e outros locais. Elas não averiguam, portanto, a redispersão da contaminação para o ar ambiente. Uma delas, ao utilizar avental e máscara juntamente com propés no grupo controle, para cuidar de pacientes transplantados, inviabiliza verificar o papel isolado do propé com a contaminação e a infecção de pacientes. Mesmo assim, seu resultado não mostrou significância entre uso e não uso desses componentes.

\section{CONCLUSÃO}

Pesquisas que utilizam análises microbiológicas são problemáticas devido aos variados métodos de coleta de amostras, locais, meios de cultura, formas e períodos de incubação. Conclui-se pela necessidade preliminar de validação e padronização desses métodos, para então serem utilizados com segurança e possibilidade de comparação de seus resultados. Enquanto isso, as pesquisas disponíveis permitem forte sugestão de que a contaminação do piso não contribui para a contaminação do ar ambiente em condições rotineiras de trabalho em centro cirúrgico, tampouco para a contaminação ou infecção do sítio cirúrgico. Por outro lado, elas permitem fortes evidências quanto a: a) capacidade de barreira microbiana depende do tipo de cobertura de sapatos; b) solas de sapatos comuns, privativos e propés interferem na transferência de microrganismos de uma área do piso para outra; c) propés e sapatos privativos ou limpos transferem menos contaminação do que sapatos comuns; d) dependendo da forma como são realizadas as operações de colocação e remoção de propés e sapatos privativos, há risco de contaminação ocupacional.

A continuidade de uso de propés ou sapatos privativos

\footnotetext{
* Esses estudos citados foram todos apresentados no Symposium of the Society for General Microbiology, dos Estados Unidos, em 1967

** Esse estudo básico é citado na seguinte publicação destes autores: Ritter MA, Marmion P. The exogenous sources and controls of microrganisms in the operating room. Orthop Nurses 1988; 7(4):23-8, porém somente seu resultado é apresentado, o que impossibilitou sua análise
} 
exclusivamente para controlar o acesso de pessoal em áreas restritas e evitar exposição ocupacional a substâncias orgânicas ainda é defendida por alguns profissionais. No entanto, ela pode obter efeitos contrários, se não for técnica e administrativamente bem controlada. Destaque-se que somente uma das pesquisas analisadas ${ }^{\star}$ encontrase citada pela Fundação Cochrane, como ensaio clínico controlado.

\section{REFERÊNCIAS BIBLIOGRÁFICAS}

1. Lacerda RA. Centro cirúrgico. In: Fernandes AT, editor. Infecção hospitalar e suas interfaces na área da saúde. São Paulo (SP): Atheneu; 2000. p. 789-818.

2. Lacerda RA. Paramentação cirúrgica: campos, gorros e propés. In: Lacerda RA, editora. Controle de infecção em centro cirúrgico: fatos, mitos e controvérsias. São Paulo (SP): Atheneu Editora São Paulo; 2003. p.289-98.

3. Kjonniksen I, Andersen BM, Sondenaa VG, Segadal L. Preoperative hair removal - a systematic literature review. AORN J 2002 May; 75(5):928-38.

4. Polit DF, Hungler BP. Fundamentos de pesquisa em enfermagem. Porto Alegre (RS): Artes Médicas; 1995.

5. Talbot LA. Principles and pratice of nursing research. St. Louis: Mosby; 1995.

6. Mangram AJ, Teresa CH, Pearson ML, Silver LC, Jarvis WR. CDC Guideline for prevention of surgical site infection, 1999. Hospital Infection Control Practices Advisory Committee. Inf Cont Hosp Epidem 1999 April; 20:250-78.

7. Agency for Health Care Policy and Research (USA). Clinical Practice Guideline Development, AHCPR Program Note. AHCPR publication $\mathrm{n}$. 93-0023. Bethesda (MD): US Departament of Health and Human Services; 1993. 